\title{
ORIGEM DOS DEPÓSITOS DIAMANTÍFEROS DE JEQUITAÍ, MINAS GERAIS, BRASIL
}

\author{
ULISSES CYRINO PENHA ${ }^{1}$ E NELSON ANGELI ${ }^{2}$
}

\begin{abstract}
RESUMO Duas questões sobre a geologia da região de Jequitaí (MG) são motivo de divergência na literatura. A primeira é de natureza genética: os depósitos diamantíferos garimpados a leste de Jequitaí resultaram efetivamente do intemperismo das rochas glaciogênicas da Formação Jequitaí e de subsequentes reconcentrações fluviais? A segunda é de natureza estratigráfica: os conglomerados destes depósitos são correlacionáveis aos conglomerados da Serra da Água Fria? Conquanto não tenham sido ainda estudadas feições de superfície dos cristais de diamantes desta área, os seguintes dados de campo sugerem que tais depósitos não devem ser caracterizados exclusivamente como elúvios da sequiência glaciogênica neoproterozóica (Formação Jequitaí): (1) o substrato dos garimpos é representado por quartzitos do Supergrupo Espinhaço, metassedimentos glaciais da Formação Jequitaí, diabásios da Suíte Metaígnea Pedro Lessa e metapelitos do Grupo Bambuí, (2) a presença de clastos com marcas de impacto e de seixos de quartzo notavelmente arredondados em alguns dos garimpos denota a participação de agentes fluviais em sua gênese, não excluindo a possibilidade de que uma parcela dos clastos originou-se dos metatilitos (3) parte dos sedimentos diamantíferos terciários infiltrou-se em fraturas dos metatilitos neoproterozóicos da Formação Jequitaí (no garimpo da Coruja), e mesmo em quartzitos mesoproterozóicos do Supergrupo Espinhaço (nos garimpos Pau-de-Fruta e Serra Preta). A impossibilidade de se correlacionar os conglomerados terciários diamantíferos dos garimpos a leste de Jequitaí com aqueles situados na Serra da Água Fria (atribuídos ao Eocretáceo), restringe consideravelmente o potencial geológico para diamantes destes últimos, uma vez que não se conhecem ocorrências de diamantes nesta serra.
\end{abstract}

Palavras-chave: diamante, glacial, Formação Abaeté, Jequitaí, Serra da Água Fria

\begin{abstract}
THE ORIGIN OF THE DIAMONDIFEROUS DEPOSITS OF THE JEQUITAI TOWN, MINAS GERAIS, BRAZIL TWO questions involving the geology of the Jequitaí region (Minas Gerais State) are discussed in the literature. The first considers that the diamond deposits located to the east of the Jequitai town and worked by itinerant prospectors are the result of the weathered glaciogenic rocks of the Jequitai Formation, followed by fluvial reconcentration, and the second question is related to the stratigraphic correlation between the mined conglomerates to those of the Água Fria ridge. The following field data suggest that these deposits are not exclusively characterized as eluvial deposits of the Neoproterozoic glaciogenic sequence (Jequitaí Formation): (1) the basement rocks of the mined sediments are constituted by quartzites of the Espinhaço Supergroup. glacial metasediments of the Jequitaí Formation, diabases of the Pedro Lessa Meta-magmatic Suite, and metapelites of the Bambui Group, (2) the presence of clasts with impact marks and well rounded quartz pebbles in some deposits indicate the importance of fluvial agents in its origin, (3) a portion of the Late Tertiary diamondiferous sediments penetrates fractures of the Neoproterozoic metasiltstones of the Jequitai Formation (Coruja deposit), and even in Mesoproterozoic quartzites of the Espinhaço Supergroup (Pau-de-Fruta and Serra Preta deposits). The impossibility to correlate the mineralized Tertiary conglomerates east of Jequitaí with those localized in the Água Fria ridge (Abaeté Formation of Cretaceous age) limits considerably the geological potential for diamond of the latter, due to the fact that diamond occurrences in this ridge are, so far, unknown.
\end{abstract}

Keywords: diamond, glacial, Abaeté Formation, Jequitai, Água Fria ridge

INTRODUÇÃO Os depósitos diamantíferos de Jequitaí, centro-norte de Minas Gerais (Fig. 1), são trabalhados por garimpeiros desde o último quartil do século XIX e foram interpretados por Derby (1882) como elúvios relacionados ao intemperismo das rochas glaciogênicas da Formação Jequitaí. Embora a literatura ofereça um considerável número de trabalhos sobre o tema, persistem dúvidas quanto à efetiva proveniência glacial dos diamantes desta área, problemática que se aplica a outras regiões diamantíferas de Minas Gerais (Penha et al. 2000).

Nos anos de 1997 e 1998 a Companhia Mineradora de Minas Gerais (Comig) desenvolveu trabalhos exploratórios em áreas situadas $25 \mathrm{~km}$ ao sul de Jequitaí, na Serra da Água Fria, objetivando avaliar preliminarmente o potencial diamantífero dos conglomerados que ocorrem sob uma extensa cobertura arenosa. Após participar dos trabalhos citados, o primeiro autor deste artigo empreendeu estudos acadêmicos em conglomerados diamantíferos dos garimpos situados a leste da cidade de Jequitaí e nas imediações de Francisco Dumont (extremo norte da Serra do Cabral), buscando comparações entre estes dois conjuntos.

Naquela ocasião, foram testadas duas hipóteses de trabalho: uma que correlaciona os conglomerados da Serra da Água Fria aos dos garimpos de diamante localizados a leste de Jequitaí (Gonzaga 1997) e outra que trata do transporte glacial neoproterozóico dos diamantes e de sua concentração fluvial subseqüente gerando os depósitos (Gonzaga \& Dardenne 1991). Apresenta-se a seguir uma descrição factual dos depósitos diamantíferos de Jequitaí, a qual embasou uma proposição sobre a origem dos mesmos.

DESCRIÇÃO DOS DEPÓSITOS Os conglomerados situados a leste de Jequitaí ocupam uma área $<20 \mathrm{~km}^{2}$ entre as serras da Água Fria e das Porteiras, balizada pelo rio Jequitaí a Sul e córrego do Sítio a Norte, onde estão os garimpos da Lavrinha, Pau-de-Fruta, Urucum, Serra Preta e Coruja. Os teores de diamante destes depósitos se situam em geral entre 0,04 e $0,16 \mathrm{ct} / \mathrm{m}^{3}$. Ainda que sejam enfatizadas na literatura as pequenas dimensões da maioria dos diamantes da região (Chaves 1997), é oportuno registrar: (1) que Freyberg (1934) menciona um diamante de $23 \mathrm{ct}$ no córrego do Carrapato, afluente esquerdo do rio Jequitaí e com nascentes na Serra da Água Fria (Fig. 1), e (2) que alguns autores relatam recentemente a extração de um diamante com $11,83 \mathrm{ct} \mathrm{em}$ garimpo situado a leste

I Docegeo/CVRD - Br 262, km 296, Caixa Postal 09, 330I0-970. Santa Luzia/MG - ulisses@cvrd.com.br

2 Depto de Petrologia e Metalogenia do IGCE-UNESP. Av. 24A, 1515, 13506-900. Rio Claro/SP - nangeli@rc.unesp.br 


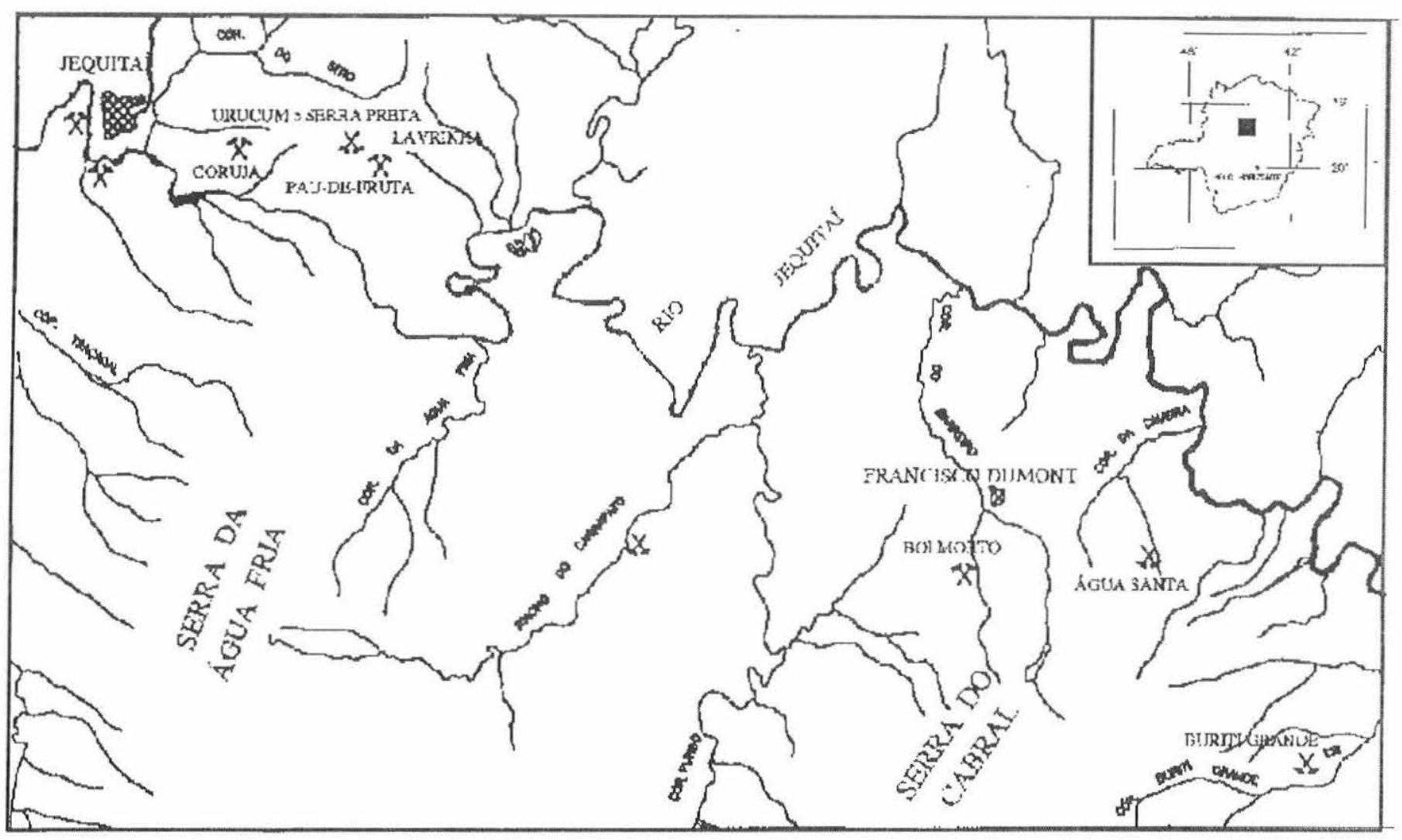

Figura I - Localização dos garimpos de diamante abordados em relação às cidades de Jequitaí e Francisco Dumont, norte de Minas Gerais. As bordas das serras da Água Fria (principalmente) e do Cabral (em pequena escala) são sustentadas por conglomerados cretáceos da Formação Abaeté, cuja erosão têm fornecido sedimentos e diamantes à bacia do Rio Jequitaí.

de Jequitaí (e.g. Bottino 2000).

Garimpo da Lavrinha Situa-se entre $812 \mathrm{~m}$ e $839 \mathrm{~m}$ de altitude (Fig. 2). A descrição das catas garimpeiras e de um poço de pesquisa permitiu estabelecer um perfil geral do depósito, assentado sobre rochas mesoproterozóicas quartzíticas do Supergrupo Espinhaço, metatilitos da Formação Jequitaí e intrusivas máficas da Suíte Metaígnea Pedro Lessa (as duas últimas unidades são neoproterozóicas). O minério principal consiste de conglomerado suportado predominantemente por clastos com matriz arenosa oxidada, definindo um horizonte com espessura irregular entre 0,7 e 1,5 m. Os clastos, em geral com $5-8 \mathrm{~cm}$ de eixo maior e localmente atingindo $50 \mathrm{~cm}$, são via de regra friáveis e compostos por quartzitos, scixos de quartzo com notável arredondamento e concreções lateríticas, em ordem decrescente de abundância. Acima ocorre um horizonte laterítico ferruginoso $(0,2-0,8 \mathrm{~m})$ sob a forma de pequenos nódulos e de clastos com até $50 \mathrm{~cm}$, por vezes subarredondados, imersos em matriz areno-argilosa oxidada. Quando enriquecido em pequenos seixos de quartzo bem arredondados, este horizonte porta diamantes, correspondendo possivelmente ao conglomerado cretáceo da Formação Abaeté retrabalhado (com destruição parcial dos clastos friáveis de quartzito) e em estágio avançado de lateritização (Fig. 3). Completam o perfil do depósito areias castanhas silto-argilosas com espessura de 0,2-3,0 m.
Garimpo Pau-de-Fruta Situa-se a oeste do da Lavrinha (Fig 2), somente uma cata encontrava-se ativa quando de sua descrição. Nesta, o embasamento consiste de quartzitos fraturados do Supergrupo Espinhaço, embora também aflore encosta abaixo um horizonte decimétrico da porção basal do metatilito da Formação Jequitaí com pavimento intratilítico estriado. O minério diamantífero, com espessura de 0,05-0,25 $\mathrm{m}$, compreende fragmentos de laterita $(80 \%)$ e de quartzo de veio e de quartzito (20\%, incluindo os bem arredondados), imersos em matriz arenosa. O minério freqüentemente preenche fraturas nos quartzitos, razão pela qual os garimpeiros removem grande quantidade de blocos quartzíticos. O topo do perfil é composto por areias castanhas sílticas com espessura máxima de $0,4 \mathrm{~m}$.

Garimpo do Urucum Situa-se entre os garimpos da Coruja e Pau-de-Fruta (Figs. 1 e 2), encontrava-se inativo e ocupa uma área aproximada de $500 \mathrm{~m} \times 150 \mathrm{~m}$ entre as cotas de 780 e $800 \mathrm{~m}$. O embasamento exposto do depósito consiste de quartzitos do Supergrupo Espinhaço. A cata estudada tem como minério uma camada com $0,6-1,0 \mathrm{~m}$ de conglomerado com clastos quartzíticos friáveis de $0,05-0,40 \mathrm{~cm}$ em matriz arenosa. Sobreposta a esta ocorre um horizonte com 0,3-0,6 m, rico em pisólitos lateríticos com quartzo agregado e em seixos de até $2,5 \mathrm{~cm}$ com elevado grau de arredondamento. O topo compreende areias argilosas vermelhas com grânulos de quart- 


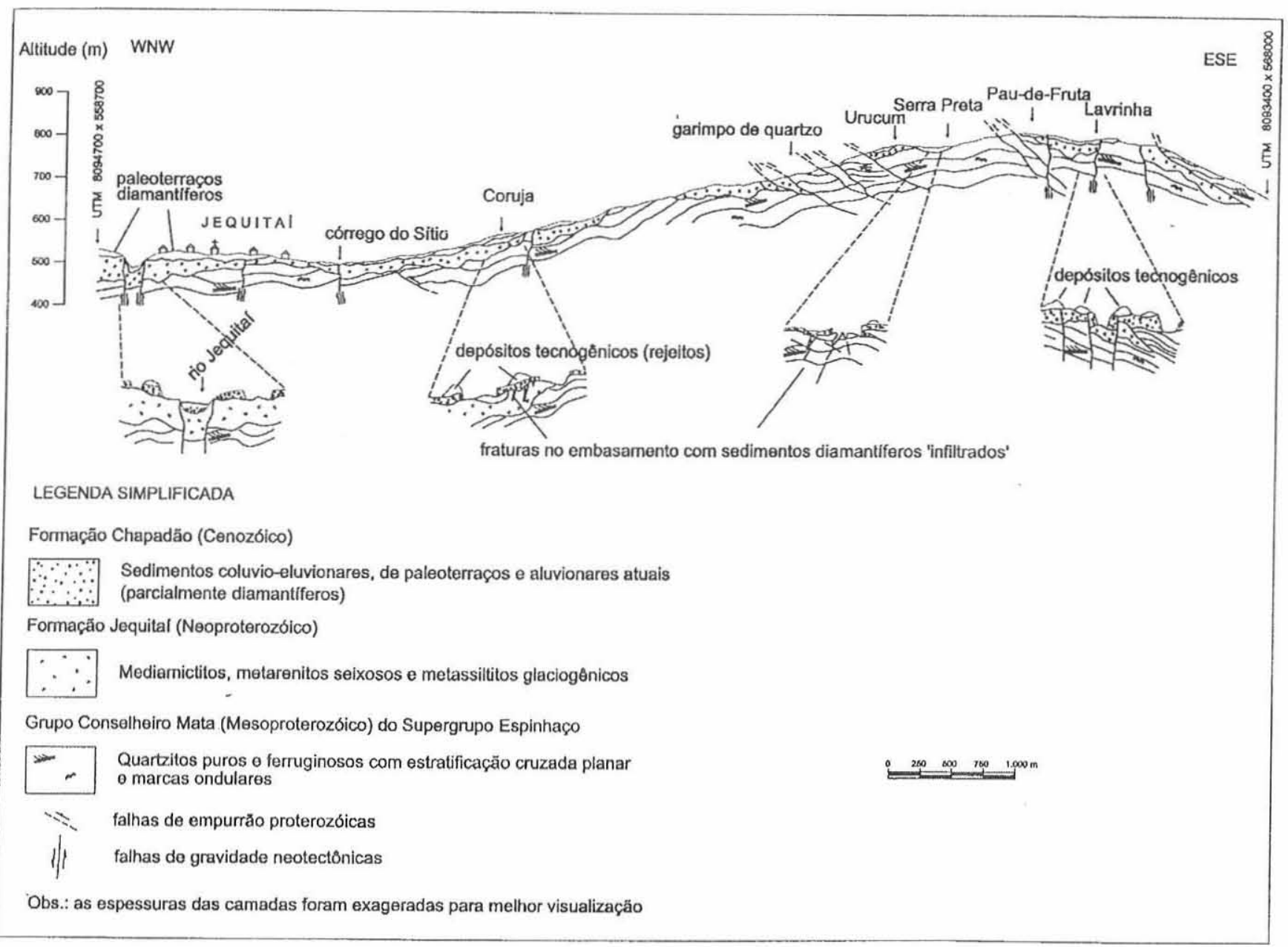

Figura 2 - Perfil geológico simplificado entre a cidade de Jequitaí e o garimpo da Lavrinha. Notar que o substrato dos garimpos, exceto nos depósitos de paleoplacers do rio Jequitaí, é representado não apenas por rochas glaciogênicas da Formação Jequitaí, mas também por quartzitos do Supergrupo Espinhą̧o.

zo e nódulos lateríticos, com espessura variável entre $3 \mathrm{~m}$ e, localmente (Joachim Karfunkel com. verbal), $15 \mathrm{~m}$.

Garimpo da Serra Preta Corresponde a uma faixa ligeiramente saliente na topografia, posicionada entre os garimpos do Urucum e Pau-de-Fruta (Fig. 2). Sua denominação se deve à coloração escura oriunda do intemperismo dos quartzitos do embasamento removidos pela garimpagem. Embora faça contato lateral com o depósito do Urucum, seu capeamento estéril inexiste ou tem espessura na casa do decímetro. O minério, com espessura máxima de $0,2 \mathrm{~m}$, compõe-se de pisólitos e fragmentos lateríticos, pequenos seixos bem arredondados de quartzo e quartzito e fragmentos de veios de quartzo em matriz arenosa. O minério ocorre ainda preenchendo fraturas nos quartzitos.

Garimpo da Coruja Situa-se às margens da estrada que liga Jequitaí ao garimpo Pau-de-Fruta e é o maior garimpo ativo no município, ainda que de forma incipiente, estendendo-se da altitude $730 \mathrm{~m}$ encosta abaixo até quase alcançar a margem direita do rio Jequitaí, na cota $510 \mathrm{~m}$ (Fig.2). O horizonte mineralizado assenta-se predominantemente sobre metatilitos e metarenitos da Formação Jequitaí, por vezes cortados por enxames de veios de quartzo e, com menor freqüência, sobre quartzitos e lentes metaconglomeráticas do Supergrupo Espinhaço. Nos perfis das catas estudadas, a cobertura arenosa tem espessura centi-decimétrica e o horizonte mineralizado apresenta possança de $0,2-1,5 \mathrm{~m}$, com média em torno de 0,6 $\mathrm{m}$. Neste, são freqüentes fragmentos de laterita, clastos friáveis de quartzito puro e ferruginoso de até $0,6 \mathrm{~m}$ com marcas de impacto (percussion marks), cristais de quartzo pouco transportados, seixos de quartzo e quartzito bem arredondados em uma matriz areno-argilosa com grânulos, além de calhaus de rocha carbonática (provavelmente do Grupo Bambuí, neoproterozóico), um deles com $1,1 \mathrm{~m}$ de eixo maior. Nas porções mais elevadas do depósito da Coruja o perfil mostra-se completo, com conglomerado rico em fragmentos de quartzitos do Supergrupo Espinhaço desorganizados (Fig. 4), suportados por matriz areno-argilosa atingindo 1,5 $\mathrm{m}$ de espessura, não tendo sido observados clastos de metatilitos nas partes altas do garimpo. Descendo a topografia, rumo ao rio Jequitaí e córrego do Sítio, o perfil do depósito está modificado, com incorporação de clastos de rochas da Formação Jequitaí. De modo similar ao observado nos garimpos Pau-de-Fruta e Serra Preta, 


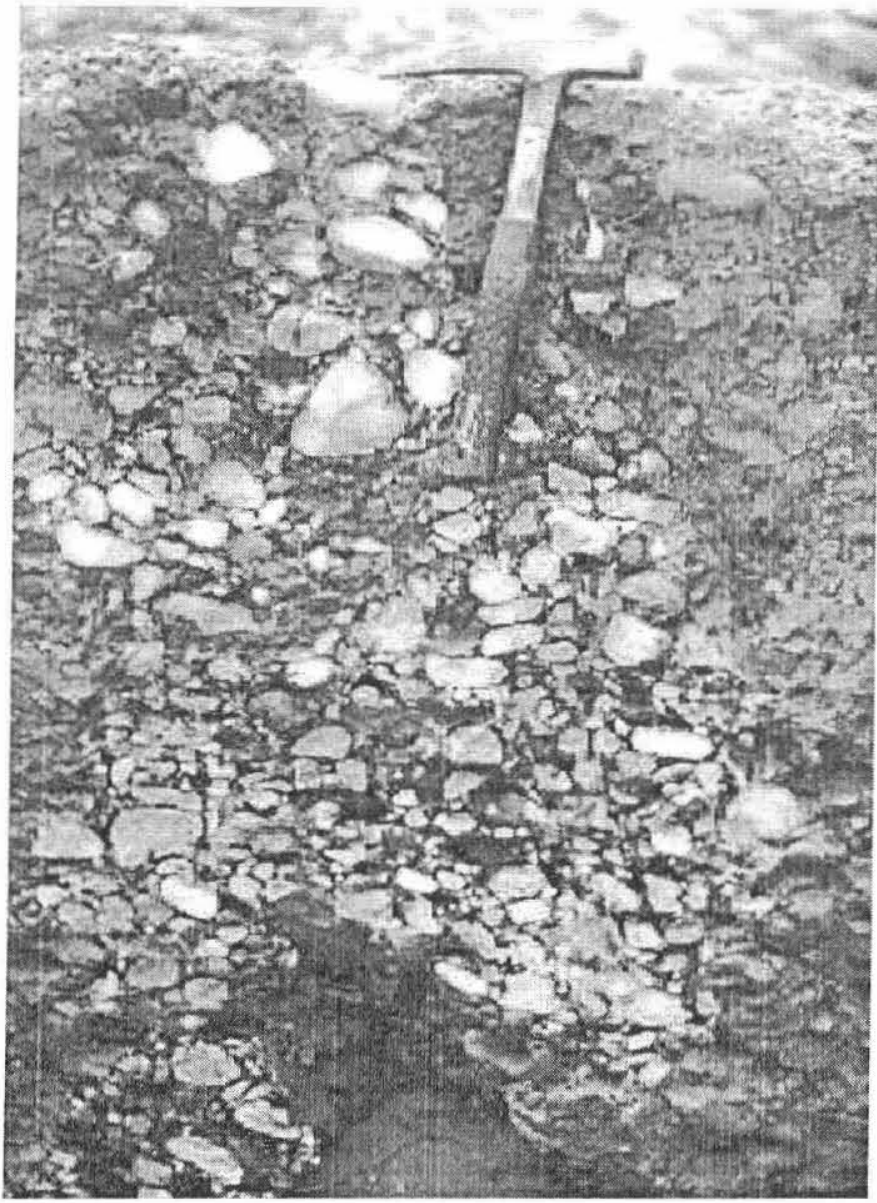

Figura 3 - "Cata do Baú" no garimpo da Lavrinha, a leste de Jequitaí. Conglomerados da Formação Abaeté (Cretáceo) retrabalhados no Cenozóico, gerando minério diamantífero friável e oxidado.

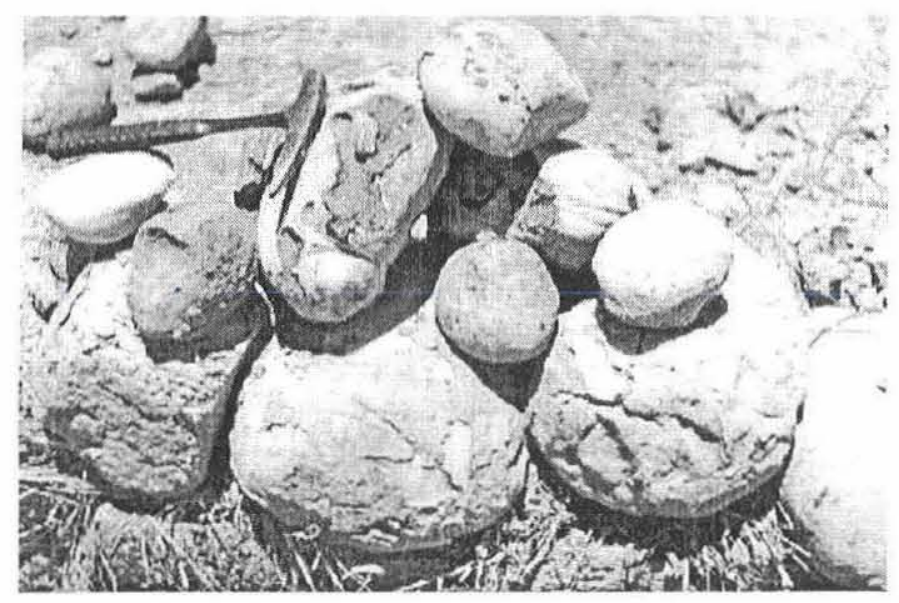

Figura 4 - Conjunto de clastos de quartzito do Supergrupo Espinhaço que integram o depósito diamantífero (cenozóico) do garimpo da Coruja, a leste de Jequitaí. O arredondamento, interpretado como aluvionar; é possivelmente herdado dos processos fluviais que deram origem aos conglomerados (cretáceos) da Formação Abaeté.

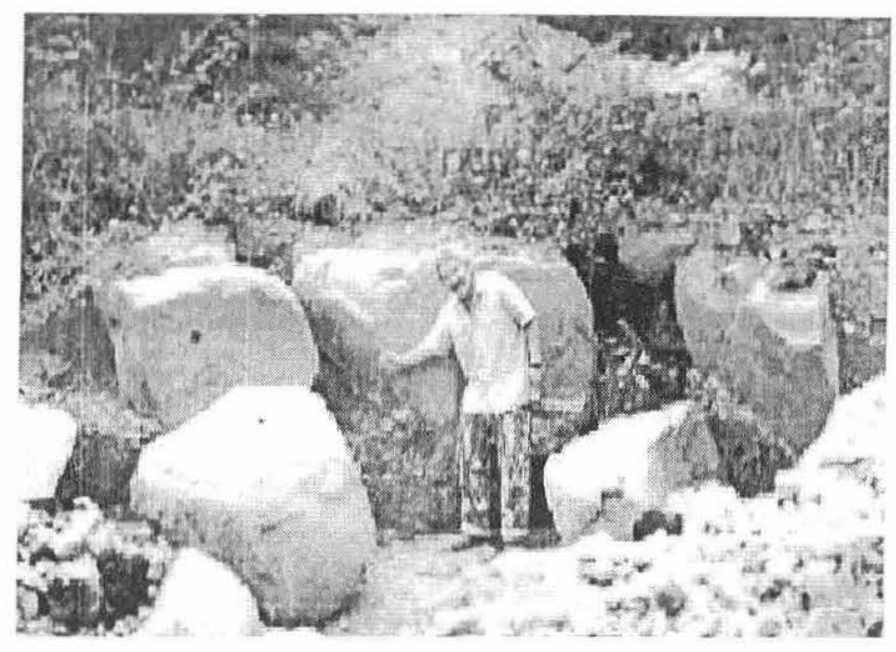

Figura 5 - Esfoliação esferoidal em metatilito maciço da Formação Jequitaí. Esta unidade neoproterozóica de origem glacial constitui grande parte do substrato do garimpo da Coruja. Notar infiltração, através das fraturas, dos sedimentos (diamantíferos) cenozóicos que capeiam o metatilito. Os garimpeiros lavram o horizonte mineralizado acima dos metatilitos e os sedimentos que preenchem as fraturas.

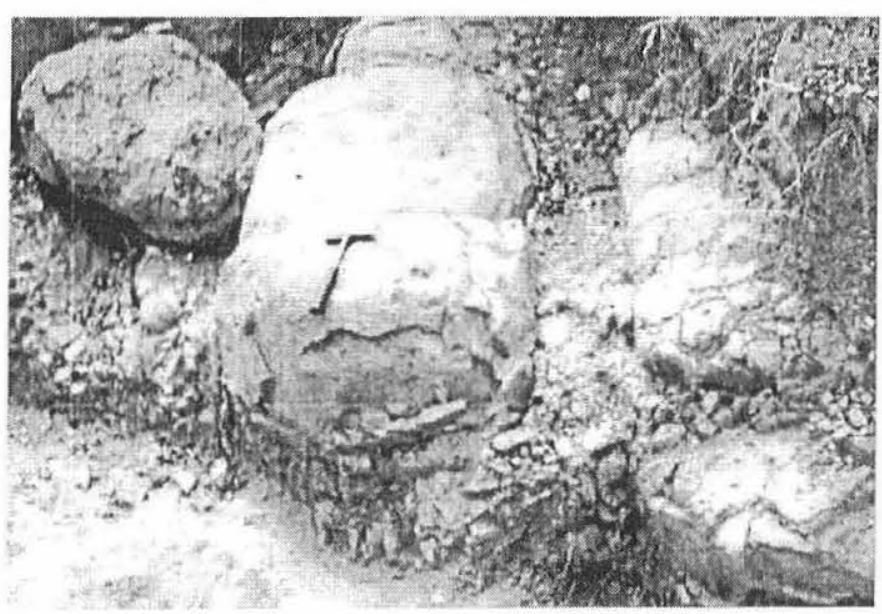

Figura 6 - Detalhe da esfoliação do metatilito neoproterozóico com infiltração de sedimentos cenozóicos diamantíferos nas fraturas. Garimpo da Coruja, a leste de Jequitaí.

nota-se em algumas catas infiltração de sedimentos diamantíferos em fraturas do substrato proterozóico (Figs. 5 e 6).

CORRELAÇÃO ENTRE OS CONGLOMERADOS DE JEQUITAÍ E OS DA SERRA DA ÁGUA FRIA A hipótese de correlação entre os conglomerados dos garimpos citados e os situados na Serra da Água Fria, de Gonzaga (1997), deve ser reconsiderada em função de evidências levantadas por Penha (2001): (1) o posicionamento altimétrico dos dois conjuntos é muito diverso, isto é, os conglomerados dos garimpos ocorrem entre 510 e $839 \mathrm{~m}$ de altitude e os da serra, entre 875 e $1003 \mathrm{~m}$; (2) as formas de relevo são onduladas nos garimpos 
e notavelmente aplanadas na serra, caracterizando nesta um chapadão; (3) a espessura dos conglomerados situa-se entre 0,4 e 1,5 m nos garimpos, podendo atingir $35 \mathrm{~m}$ na borda sul da serra; (4) não há organização do arcabouço nos conglomerados de Jequitaí e são comuns, nos da serra, estruturas como imbricamento de clastos e estratificação plano-paralela; e (5) um horizonte laterítico com até $6 \mathrm{~m}$ de espessura constitui o topo dos conglomerados na Serra da Água Fria, sendo que fragmentos de laterita retrabalhada ocorrem em qualquer posição do perfil dos depósitos da Lavrinha, Pau-de-Fruta e Coruja.

O nível laterítico mencionado ocorre extensivamente nas chapadas da região e sua idade é atribuída na literatura ao Mioceno Médio. Ele baliza a Superfície Sul-Americana (King 1956) e o seu desmantelamento, provocado por uma tectônica jovem - pois em alguns locais da Serra apresenta estriado e brechado - e pelos processos erosivo-deposicionais associados, clastos que foram incorporados aos conglomerados dos garimpos de Jequitaí e Francisco Dumont. Desta forma, pode-se assumir uma idade menor que o Mioceno Médio para os conglomerados dos garimpos. Por sua vez, os conglomerados da Serra da Água Fria, depositados em ambiente fluvial entrelaçado de alta energia e parcialmente retrabalhados por agentes eólicos, são atribuídos à Formação Abaeté do Grupo Areado (Eocretáceo da Bacia Sanfranciscana), não devendo ser correlacionados aos conglomerados dos garimpos.

\section{ORIGEM DOS DEPÓSITOS DIAMANTÍFEROS}

A

questão da proveniência dos diamantes contidos nos conglomerados de Jequitaí carece, para sua elucidação, de estudos complementares que investiguem as feições de superfície dos cristais de diamante. A despeito disso, algumas interpretações podem ser sugeridas no tocante à geologia destes depósitos, tendo por base os dados apresentados. Onde está mais bem preservado (porções mais altas), o conglomerado diamantífero da Coruja não contém clastos de rochas glaciogênicas, indicando que os tills e eskers neoproterozóicos da Formação Jequitaí não supriram de diamantes esta porção do depósito, conforme preconizado por Gonzaga \& Dardenne (1991) e Costa et al. (1997). No garimpo da Coruja, muitas fraturas dos metatilitos intemperizados da Formação Jequitaí estão preenchidas por sedimentos diamantíferos terciários 'infiltrados' (Figs. 5 e 6 ). O depósito não deve ser interpretado em sua totalidade como um elúvio desenvolvido sobre a Formação Jequitaí, embora em sua porção inferior seja provável a participação de processos coluvio-eluvionares devido à acentuada topografia, interpretação reforçada pela incorporação de clastos de metatilitos nos sedimentos da encosta e pela presença de quartzo com evidências de curto transporte. O embasamento dos garimpos Serra Preta (totalmente) e Pau-de-Fruta (em sua maior parte) é representado pelo Supergrupo Espinhaço e não pela Formação Jequitaí (Fig. 2), cujas fraturas em quartzitos estão, em grande número, preenchidas pelo minério diamantífero terciário (Penha 2001).

De maneira similar, os depósitos diamantíferos que bordejam as meias e baixas encostas setentrionais da Serra do Cabral (município de Francisco Dumont, Fig. 1) assentam-se sobre rochas do Grupo Bambuí, no garimpo do Boi Morto e na parte baixa do garimpo Buriti Grande, e sobre as do Supergrupo Espinhaço, no garimpo da Água Santa e na parte alta do Buriti Grande. Apenas a porção média do depósito do Buriti Grande tem como substrato a Formação Jequitaí, o que impossibilita considerar os metassedimentos glaciais desta unidade como fonte exclusiva dos diamantes de Francisco Dumont, o mesmo sendo válido para a área de Jequitaí.

$\mathrm{O}$ modelo de uma fonte única para os diamantes da região é, portanto questionável. Um retrabalhamento de conglomerados cretáceos incipientemente mineralizados em diamantes, constituindo os depósitos aqui abordados (Karfunkel \& Chaves 1995, Penha 2001), com uma eventual (e pequena) contribuição de diamantes oriundos das rochas glaciogênicas da Formação Jequitaí, é uma explicação mais razoável para a sua gênese. Esta contribuição necessita de investigação para ser comprovada, pois o volume de sedimentos do tipo esker da Formação Jequitaí - em tese os únicos sedimentos gerados em subambiente glacial concentrador de diamantes -, é insignificante se comparado ao volume dos outros sedimentos desta unidade glaciogênica na região, como metassiltitos, metavarvitos (não concentradores) e metatilitos (dispersores).

Agradecimentos Ao CNPq, por subsidiar a Tese de Doutorado do primeiro autor, da qual este artigo é síntese parcial, à Diretoria da Comig, pelo acesso a relatórios internos e ao desenhista de Cad Pedro Paulo da Luz (Comig), pela digitalização da figura; expressamos nossa gratidão. Ao professor Joachim Karfunkel (UFMG), pelas férteis discussões em campo, seguem também nossos agradecimentos. Aos revisores da RBG pelas sugestões ao manuscrito.

\section{Referências}

Bottino E. 2000. Caracterização dos diamantes da região de Jequitai-MG. Universidade Federal de Minas Gerais, Belo Horizonte, Dissertação de Mestrado, $133 \mathrm{p}$.

Chaves M.L.S.C. 1997. Geologia e mineralogia do diamante da Serra do Espinhaço em Minas Gerais. Universidade de São Paulo, São Paulo, Tese de Doutoramento, $289 \mathrm{p}$

Costa K.V., Penha U.C., Araújo M.C. 1997. Conglomerado cretáceo com potencial diamantífero na Serra da Água Fria/MG. In: SBG, Simp. Geol. Minas Gerais, 9, Ouro Preto. Anais, 14:132-133.

Derby O.A. 1882. Models of occurrence of the diamond in Brazil. American Journal of Science, 24:34-42.

Freyberg B. 1934. Die Bodenschätze des Staates Minas Gerais (Brasilien). Stuttgart, Germany: $453 \mathrm{p}$.
Gonzaga G.M. 1997. Avaliação preliminar do potencial diamantífero dos conglomerados da região da Serra da Água Fria, Município de Jequitaí/MG. Geoexplore Consultoria Mineral Lıda/Comig, Belo Horizonte, inédito:5 p.

Gonzaga G.M. \& Dardenne M.A. 1991. The Jequitai Glaciation and the dispersion of diamonds during Upper Proterozoic. In: CPRM, Intern. Kimberlite Conference, 5, Araxá. Field Guide Book, Sp. Publ.:89-93.

Karfunkel J. \& Chaves M.L.S.C. 1995. Conglomerados cretácicos da Serra do Cabral,MG: um modelo para a redistribuição colúvio-aluvionar dos diamantes do médio São Francisco. Geociências, 14(1):59-72.

King L.C. 1956. A geomorfologia do Brasil Oriental. Revista Brasileira de Geografia, 18:147-265.

Penha U.C. 2001. Geologia dos Conglomerados Cretáceos da Serra da Água Fria e dos Depósitos Diamantíferos de Jequitaí-MG. Universidade Estadual 
Paulista, Rio Claro, Tese de Doutoramento, 148 p.

Penha U.C., Karfunkel J., Magalhães P.C.V., Costa K.V., Vohl E., Hartmann M.B. Sabóia L.A., Nassif M.A., Gonzaga G.M., Campos J.E.G, Chaves M.L.S.C, Reinhardt M.C. 2000. Diamante em Minas Gerais: concepção de um Sistema de Informações Geográficas de apoio às pesquisas acadêmica e exploratória (Parte 1). Origens e potencial geológico (Parte 2). Geociências, $14(2): 25$.

Manuscrito A-1286

Recebido em 18 de novembro de 2001 Revisão dos autores em 30 de novembro de 2001 Revisão aceita em 02 de dezembro de 2001 